\title{
LA SEPARACIÓN DE PODERES EN LA PRIMERA CONSTITUCIÓN ESPAÑOLA
}

\author{
Enrique Díaz Bravo* \\ Universidad Central de Chile, Abogado
}

\begin{abstract}
Resumen: En el presente trabajo se realiza un análisis de la separación de poderes en la primera Constitución española, la de Cádiz de 1812. Comenzando con un repaso de los sucesos revolucionarios producidos a raíz de la invasión francesa, y las consecuencias que se produjeron en el ámbito político, lo que influenciado por el movimiento liberal europeo, lo que da lugar a la construcción de nuevos conceptos que permiten llevar a cabo un nuevo ordenamiento constitucional, el que sin precedentes en cuanto su integración y sobre todo por el lugar donde se residencia la soberanía, está vez en la nación.
\end{abstract}

Palabras clave: Revolución española, Constitución de Cádiz, soberanía, separación de poderes

\section{The separation of powers of the state on the first spanish constitucion}

Abstract: In this paper an analysis is made of the separation of powers in the first Spanish Constitution (1812, Cadiz). Beginning with an overview of the revolutionary events produced as a result of the French invasion and the consequences which took place in the political arena, which was influenced by the liberal movement in Europe, resulting in the construction of new concepts that allow perform a new constitutional order, which is unprecedented in its integration and especially where sovereignty is situated, now in the nation.

Keywords: Spanish revolution, Constitution of Cadiz, sovereignty, separation of powers

SUMARIO: 1. CONTEXTO Y CAUSAS DE LA REVOLUCIÓN ESPAÑOLA; 2. LAS CORTES DE CÁDIZ, REVOLUCIÓN CONCEPTUAL; 3. CORTES GENERALES Y EXTRAORDINARIAS; 3.1. Posiciones y conceptos; 3.2. La soberanía nacional; 4. LA SEPARACIÓN DE PODERES; 5. CONCLUSIONES; 6. BIBLIOGRAFÍA.

\footnotetext{
* Licenciado en Ciencias Jurídicas y Sociales, Universidad Central (Chile). Abogado por la Excma. Corte Suprema de Justicia de Chile. Máster Universitario en Derecho Constitucional, Universidad de Sevilla (España). Máster Universitario en Estudios Hispánicos, Universidad de Cádiz (España). Egresado del Máster en Evaluación de Políticas Públicas, Universidad Internacional de Andalucía (España). E-mail: enriquediaz@temasconstitucionales.com.
} 
"La soberanía es un derecho que no pueden dar ni quitar las Cortes ni está en sus facultades, porque las Cortes pueden dar leyes, pero no dar ni quitar derechos a la nación, sólo sí declararlos y asegurarlos". [Conde de Toreno. Cortes de Cádiz]

\section{CONTEXTO Y CAUSAS DE LA REVOLUCIÓN ESPAÑOLA}

Irene Castells ${ }^{1}$ afirma que con la Constitución de 1812 culmina el proceso revolucionario abierto en España por la invasión napoleónica de 1808, lo que a mi juicio, e incluso utilizando la propia argumentación que luego invoca la autora, no es del todo cierto, ya que el proceso es gatillado por la invasión, sin embargo, el verdadero proceso revolucionario comienza con la promulgación de la Constitución de Cádiz, ya que revueltas, pronunciamientos e intentonas de revolución ha habido a lo largo de toda la historia, y siguen habiendo, más lo logrado por la Constitución de Cádiz que fue institucionalizar un nuevo orden es, a mi parecer, lo verdaderamente revolucionario y el inicio de una senda, que como explica con toda claridad la autora impacto por toda la faz de la tierra.

La sociedad española, como sostiene Alberto Ramos era una sociedad estamental que estaba dividida en tres, nobleza, iglesia y el resto de los individuos. La iglesia representaba el $1,3 \%$ de la población, la nobleza el $5 \%$, sin embargo, a mi juicio no muy distante de los que ocurre en la actualidad, la concentración de las riquezas estaba en casi la totalidad en dichos estamentos, como muestra, la Iglesia concentraba $1 / 3$ de la riqueza urbana y rústica de la España peninsular. Por su parte la nobleza controlaba los cargos públicos y los señoríos que se extendían a cerca de 1300.

Es esa constitución estamental de la sociedad la que en gran mediad provoca que el 17 de marzo de 1808 ocurra el Motín de Aranjuez, por rencillas de poder internas, lo que provoca la abdicación de Carlos IV, producto del golpe de Estado de un sector de la nobleza, por lo que el 19 de marzo de 1808 se produce la entronización de Fernando VII. Esta fecha resulta del todo importante, ya que cuatro años más tarde es promulgada la constitución de Cádiz en esta fecha para celebrar la entronización de Fernando VII, quien se encontraba, supuestamente, en el cautiverio napoleónico.

Para precaver la ausencia Fernando VII se creó una Junta Suprema de Gobierno en Madrid, dentro del sistema político de gobierno, de modo que al producirse su viaje a Francia, se discute respecto a cuál sería el adecuado sistema de sustitución del poder por medio de la Regencia.

\footnotetext{
${ }^{1}$ CASTELLS OLIVÁN, Irene. La constitución gaditana de 1812 y su proyección en los movimientos liberales europeos del primer tercio del siglo XIX. p. 117-132
} 
Por las presiones de Napoleón renuncia al trono Fernando VII, tres días antes lo había hecho Carlos IV, quien cede sus derechos a Napoleón, por una abultada pensión anual. Napoleón le ofrece el trono a su germano Luis quien no acepta el encargo, nombrando finalmente a su hermano José.

Es en este contexto que se dicta la denominada Constitución de Bayona, la que es realidad es una Carta fundamental, toda vez que carece del requisito fundamental de toda Constitución moderna, cual es la relación soberanía nacional-poder constituyente. Este texto data de 8 julio 1808. A pesar del contexto político su contenido determina, a mi juicio, un marco integrador y un paso importante en el desarrollo de determinados conceptos que, en España, se miraban como anhelos por parte de ciertos sectores. Así sus rasgos más importantes los constituyen, al menos en la discusión del Estatuto:

> Igualdad entre americanos y españoles.

$>$ Libertad de producción y comercio.

> Separación de las funciones administrativas y judiciales.

$>$ Supresión de monopolios y privilegios.

$>$ Supresión de aduanas interiores.

$>$ Inviolabilidad del domicilio.

$>$ Libertad personal.

$>$ Garantías para los presos.

Producto del cautiverio del Rey, el 2 de mayo de dicho año comienza a levantarse toda España, en un proceso de insurrección espontaneo. De esta forma arribamos al proceso de constitución de Las Juntas, que puede ser denominado como el proceso de Revolución española que abarca entre 1808 y 1812. Las causas son fácilmente identificables para estos efectos, así el vacío de poder producto de la ausencia del Rey, lo que se suma a la inoperancia de la Junta de Gobierno y la inacción del Consejo de Castilla. Así comienzan a crearse las Juntas locales con carácter de autoridad administrativa en el ámbito local, representando legítimamente, a su juicio, los intereses de la Corona, militarmente.

Es este el proceso de mayor importancia, que a mi juicio, marca la diferencia entre el resto de los procesos revolucionarios conocidos hasta el momento, Estados Unidos y Francia, ya que es la ausencia del poder político constituido lo que provoca la necesidad de recuperar el país haciendo gala de conceptos que hasta el momento habían sido utilizados solo en la doctrina en España como el de Soberanía. Es a partir de la declaración de guerra a Napoleón donde la Soberanía española pretende ser reasumida por el pueblo, formula artificiosa en un territorio dominado por la monarquía históricamente, lo que no obsta que haya sido adecuada no solo para el momento político, sino para iniciar un proceso de ruptura con el antiguo orden institucional, volveremos a esto. Es importante destacar que en la propia proclama de la Isla de León, 2 de junio de 1808, se plasma esto: 
"Quando estuviésemos por la separación de los derechos al trono (que no estamos) aún entonces no habría éste de constituirse en Napoleón, por pertenecer á la Nación el dominio de la corona: si españoles: un Rey erigido sin potestad no es Rey, y la España está en el caso de ser suya la soberanía por la ausencia de Fernando su legítimo poseedor".

Así mismo, en un texto a mi juicio excepcional, al no sólo constituir una proclama política, sino también una hoja de ruta constitucional en el difícil momento institucional, el Voto de un Español, atribuido a Antonio Peña (Valladolid, agosto de 1808) se indican algunos conceptos que considero de suma importancia rescatar, principalmente los conceptos relativos a la soberanía nacional.

“Una Nación no puede prosperar sin un buen gobierno, y no puede tener este buen gobierno sin una Constitución, ó (lo que es lo mismo) sin unas leyes fundamentales que ella misma establezca, y vele sobre su observancia."

"La voluntad de los pueblos es la que hace los Reyes, y ella misma los deshace quando estos abusan de los poderes que el pueblo les ha confiado. Un Rey es un General, un Administrador nombrado por la Nación..."

“... ningún soberano tiene facultad de despojar á otro de sus trono sin el consentimiento de la nación que le proclama y le sostiene”.

"Una Monarquía hereditaria en cabeza de Fernando y sus descendientes, es la forma de gobierno que debemos adoptar, pero baxo una Constitución que modere y fije los límites de la autoridad Real, y arregle las relaciones que debe haber entre la Nación y el Rey..." Prosigue luego al respecto del poder constituyente y de los poderes constituidos "Los sabios nacionales presentarán varios proyectos razonados de Constitución, á fin de ilustrar la opinión pública, y auxiliar a nuestros representantes en Cortes, en las que se sancionará la que merezca su aprobación, y en la que se hallen mejor equilibrados el poder legislativo, el poder executivo, y el poder judicial".

Las Juntas comienzan a declarar la guerra a Francia, y a pesar de la heterogénea composición política de las Juntas en toda España existe el elemento común de la recuperación de la Soberanía mediante un poder único bajo la imagen del Rey. De este modo la unificación para algunos consistía en la creación de un cuerpo supremo único; mientras que para otros la formula era de Cortes tradicionales que sustituyeran al poder político. Así se constituye la Junta Central y Gubernativa del Reino, la que incluía representantes del antiguo régimen, la que se encontraba en pugna con el Consejo de Castilla que sostenía la necesidad de determinar la Regencia por la ausencia del Rey. Termina por imponerse la primera una vez que toma control sobre las juntas provinciales (noviembre, 1808), las que le otorgan su reconocimiento. 
Alberto Ramos sostiene que las Juntas eran poderes nuevos, sustitutivos, emanados de la "voluntad popular" que asumieron la soberanía en nombre del pueblo y la nación. Continua sosteniendo que

Dentro de este escenario de guerra es que se convocan a representantes de los territorios americanos, (enero 1809), lo que más allá del argumento de representatividad, mínima comparada con la de los peninsulares en una relación de 9 a 36, surge de la necesidad de financiar la guerra, y los recursos provenían de ultramar por lo que a mi juicio es el motivo determinante de la convocatoria, aún cuando más tarde se comprobaría que los reclamos surgidos en estos momentos por los españoles de ultramar ya no sólo respondían a falta de representación, sino a los movimientos independentistas que ya se gestaban y manifestaban en estas fechas en dichos territorios.

Una importante etapa dentro de la ratificación del nuevo orden fue la denominada "Consulta al País". La que se produce en el contexto en que la Junta Central era muy cuestionada en su gestión luego de la derrota de Ocaña, por lo que el debate en torno a la necesidad de convocar a Cortes. Luego de la realización de la consulta, limitada a ciertas personalidades, la que verso entre otras otra materias a la forma de constituir las Cortes, ya estamentalmente o en base a criterios de la población del país, donde triunfa este último criterio, es que se ratifica el espíritu mayoritario de dar un vuelta en la forma de organización del poder político, el que a pesar de encontrarse concentrado en la Corona, existían una serie de poderes intermedios que convivían con la monarquía, estos eran los señoríos, que ejercían un poder cuasi absoluto dentro de sus territorios. Volveremos a esto más adelante. Esto es lo que los movimientos liberales, a través de la prensa y políticamente como en el caso de la consulta en cuestión, es que comienza a modificarse transitando hacia la constitución de un orden basado en la Soberanía nacional.

Es en enero de 1810 cuando comienza a decantarse el proceso para arribar a las Cortes de Cádiz, ya que la Junta Central, desacreditada, como dijésemos por su administración en la guerra, se disuelve a favor del Consejo de Regencia. Antes de renunciar la Junta convoca a Cortes Generales lo que es ratificado posteriormente por el Consejo de Regencia. En estas condiciones se constituye la Junta Suprema de Cádiz la que coexiste con el Consejo de Regencia, la primera administrando exclusivamente la Hacienda.

\section{LAS CORTES DE CÁDIZ, REVOLUCIÓN CONCEPTUAL}

A partir de la inauguración de las Cortes de Cádiz (1810) se comprueba, sostiene Benjamín González Alonso (1987.), la aparición de otro lenguaje, de nuevos conceptos, de otra visión del orden político que subyace al articulado de los dos 
primeros decretos de las Cortes, que tendrán cumplido desarrollo en la Constitución de 1812.

Los nuevos conceptos son, primero la idea de Soberanía, cuyo titular ha sido desplazado desde el rey, legitimado divinamente, hacia la nación, lugar donde se residencia la soberanía, de modo que técnicamente se provoca una división entre la titularidad y el ejercicio de dicho poder, lo que anteriormente al concentrarse la titularidad y el ejercicio del poder en un solo individuo no surgía problema. Ahora deben existir representantes que ejerzan como delegados de la Nación dicho poder, de modo que observamos como el concepto de soberanía nacional provoca ineludiblemente dos efectos, la separación de la titularidad del poder y su ejercicio ordinario por medio de representantes, es decir surge la ligazón ineludible entre Estado constitucional y Estado representativo. ${ }^{2}$

En segundo término, el Estado constitucional logra identificarse en el sistema de División de Poderes, de modo de garantizar que el ejercicio de las funciones propias del Estado, como manifestaciones de la soberanía, sean depositadas y ejecutadas por distintos centros. En tercer lugar, otro rasgo del Estado constitucional es el sistema de derechos individuales, donde se establece que el hombre es titular de una serie de derechos que responden a su propia naturaleza por lo que tienen el carácter de inalienables e imprescriptibles. Este reconocimiento de ciertos derechos naturales permite fundamentar la igualdad jurídica entre los individuos en primer término, y entre los individuos y el Estado y sus órganos. Finalmente, es el Estado de Derecho, entendido como el sometimiento de los poderes públicos a la ley, como emanación de la voluntad soberana, lo que configura el Estado constitucional.

Como sostiene Pérez Royo (1992.) el Estado Constitucional se caracteriza por constituir una forma política que, al disolver las relaciones de supra $y$ subordinación políticas que se extendían por toda la superficie de la sociedad, los poderes intermedios, las desigualdades de iure, potenciaba la libertad del individuo, lo convertía en un instrumento de liberación."

\section{CORTES GENERALES Y EXTRAORDINARIAS}

Es en enero de 1810 cuando comienza a decantarse el proceso para arribar a las Cortes de Cádiz, ya que la Junta Central, desacreditada, como dijésemos por su administración en la guerra, se disuelve a favor del Consejo de Regencia. Antes de renunciar la Junta convoca a Cortes Generales lo que es ratificado posteriormente por el Consejo de Regencia. En estas condiciones se constituye la

\footnotetext{
${ }^{2}$ Véase ALONSO, Benjamín G. Del estado absoluto al estado constitucional. p. 86
} 
Junta Suprema de Cádiz la que coexiste con el Consejo de Regencia, la primera administrando exclusivamente la Hacienda.

Así, se produce la convocatoria a Cortes, en cuanto a su contenido y función se sostiene que la Constitución para las Cortes no será nueva, sino que tendrá por objeto el restablecer y mejorar la Constitución fundamental de España. En cuanto a su composición, la elección, primeramente, era censitaria por renta, mientras que en su número no existe acuerdo entre los historiadores, sin embargo el número más razonable según los antecedentes que no superaban los 240, aún cuando asistieron más personas.

En cuanto a la composición ideológica de las Cortes generales y extraordinarias, el profesor Alberto Ramos sostiene que existían tres sectores generales en las Cortes, Liberales, Conservadores y Absolutistas. Cada uno de los sectores contaba con distintas tendencias en su interior, aún cuando no se puede hablar de partidos políticos ni de grupos ideológicos, cuestión que suscita debate, como veremos en los acápites siguientes. En el caso de los diputados americanos, estos actuaron como un grupo de presión, luchas de los ciudadanos como proyecto político, y el principio de representación como eje de su posición. Cabe consignar al respecto a los americanos son convocados, además de haber incorporado políticamente dicho derecho, de forma inevitable para los españoles, debido a que el propio Napoleón los convoca a Bayona, de forma tal que no podías por una parte no ser incorporados mientras ya se observaban protestas políticas en los territorios de ultramar, sin perjuicio del verdadero espíritu integrador de parte de ciertos sectores, no sólo liberales, de incorporar efectivamente en la representación de la Nación española a los americanos ${ }^{3}$, consignando primero la igualdad de derechos (07/02/1810) para luego desarrollarlo en la propia Constitución.

El 24 de septiembre de 1810 se constituyeron las Cortes Generales y extraordinarias en la Isla de León, las que inician su trabajo mediante su primer Decreto en el que propone la inviolabilidad de los diputados, la soberanía de la Nación y la separación de poderes, como elementos innovadores y finalmente la labor de las Cortes da su gran fruto con la aprobación por la mayoría de los diputados. Entre tanto se realizaron grandes debates, entre los que destacaron la defensa que algunos de los diputados americanos, representantes de sus pueblos y no se determinados grupos hicieron en las Cortes, donde destaca enormemente el diputado Mexia Lequerica. Sobre este punto volveremos más adelante, ya que destaca como una de las posiciones que se sostienen respecto a la Soberanía.

\footnotetext{
${ }^{3}$ Por primera vez en la historia se incorpora representación americana en Cortes.
} 


\subsection{Posiciones y conceptos}

Joaquín Varela ${ }^{4}$ aborda la composición de las Cortes de Cádiz desde el punto de vista de la influencia de los modelos constitucionales extranjeros en los diversos Diputados. Así, sostiene que en la Cortes se debió decidir cuál de los modelos constitucionales existentes se adoptaría en España en el contexto de las Cortes post invasión napoleónica.

Entre los modelos constitucionales existentes se encontraban el inglés, difundido por los Diputados Realistas; el modelo francés, sostenido por los liberales; y el modelo constitucional de los Estados Unidos de Norteamérica.

El autor comenta su posición respecto a cada uno de ellos, así respecto al modelo de los Estados Unidos sostiene que ningún Diputado, ni aún americano, se manifestó expresamente a favor de este. Aún más, hubo manifestaciones abiertamente en contra, algunas de ellas pronunciadas por el conde de Toreno y por Agustín Argüelles, las que aludían a la necesidad de una Nación única, la que según su parecer era puesto en peligro por una distribución territorial y administrativa como la del federalismo, unido a la forma republicana de gobierno. Al respecto, el autor hace suyo un texto de Manuel Martínez Sospedra, donde se sostiene que la revolución americana habría sido una ruptura sangrienta $y$ dolorosa respecto del régimen anterior y cuyo tinte radical era notorio, de modo que por ello no habría calado esta forma de Estado, ni de gobierno, en la España de la época.

En segundo lugar se refiere al modelo constitucional inglés, que promovía un espíritu político y social conciliador y moderado, una monarquía limitada, bicameralismo y una función judicial defensora de las libertades individuales, donde destaca el rol de Lord Holland, aristócrata inglés, que influenció a muchos de los pensadores y Diputados de las época, en especial a aquellos que miraban con celo todo lo francés. Tuvo una especial influencia sobre Jovellanos, en especial en los relativo al bicameralismo y en la organización estamental de las Cortes por sobre el principio de representación nacional.

Sin perjuicio de lo anterior la posición dominante en las Cortes, liberal, no se encontraba cercana a la posición anglófona, más bien la senda seguida fue la de los franceses de 1791. De este modo la posición o modelo inglés fue apoyado por algunos de los conservadores, a diferencia de lo ocurrido en la Asamblea constituyente francesa de 1789 donde hubo sectores liberales que promovían las ideas anglófonas.

Sostiene que los motivos por los cuales el modelo inglés no encuentra adeptos en España responde a diversos motivos entre los cuales destacan la falta de conocimiento de las filosofía política, sin embargo a mi juicio responde principalmente por las profundas diferencias en los procesos de cambio, el tránsito desde el absolutismo al modelo parlamentario en Inglaterra se realiza en un contexto y tiempo distinto al español caracterizado y, sobre todo, motivado por la

\footnotetext{
${ }^{4}$ VARELA SUANZES CARPEGNA, Joaquín. Los modelos constitucionales en las Cortes de Cádiz. p. $243-268$
} 
invasión francesa. De igual manera la convivencia entre los sectores realistas y liberales en España provocan un acercamiento de las posiciones de dichos sectores, que producto de las desconfianzas mutuas, pero con la necesidad de demostrar unidad frente al enemigo francófono, deviene en el conocido modelo constitucional gaditano.

Por otra parte, no hay ninguna duda de que el influjo político y filosófico liberal proviene de los grandes pensadores franceses Rousseau, Voltaire, Montesquieu, de los que en la España invadida se renegaba públicamente y disimulaba, pero sin embargo a todas luces sus ideas se encontraban presentes en todas sus intervenciones. De este modo, desde mi perspectiva, el diseño de la idea principal y único principio inductor del proceso gaditano, la Soberanía Nacional, es de clara influencia francesa. Sin embargo las diferencias son muchas, ya desde los motivos invocados, Constitución histórica española, la lealtad a la monarquía, la religión, y sobre todo la grandes diferencias entre los Diputados, que de visiones tan antagónicas logran sobreponerse a ello, por el interés de España, buscando reconstruir un país que se encontraba fraccionado y disperso, por medio de una Constitución de profundo carácter patriótico y a su vez con instituciones modernas inspiradas en principios liberales.

Por su parte Ignacio Fernández Sarasola (2011.) sostiene que los Realistas sostenían posiciones relativas a que "el poder soberano residía in radice en la comunidad (recibido a su vez de la instancia divina) que, incapaz de ejercerlo por sí, lo habría transferido (traslatio imperii) mediante un pacto (pactum subjectionis) al Rey, quien pasaría de ese modo a ser titular in actu del poder" . La comunidad recobraba las facultades solo por la ausencia del Rey, pero que aún así las Cortes se encontraban limitadas de alterar el núcleo esencial del pacto que se manifestaba en las Leyes Fundamentales del Reino.

Por su parte los Liberales sostenían que la soberanía residía en la Nación de modo originario, de modo que no mediaba pacto alguno. La Nación correspondía a un ente abstracto no identificado con una parte de la población, sino que correspondía despersonalizadamente a todos los individuos que componían España.

Cabe destacar que, de acuerdo a lo sostenido por Castells Olivan(1989.) , respecto a las posiciones en el contexto, destaca aquella en la que sostiene que la guerra de resistencia española contra el invasor francés fue de composición interclasista, toda vez que todos los componentes de la sociedad estaban interesados, por motivos diversos, en expulsar a Francia, tanto absolutistas como los más radicales compartían este interés, luchando por la libertad, pero a su vez con la gran ambigüedad de hacerlo en nombre del Antiguo Régimen, el que una vez repuesto en el poder no vacilo en proscribir todo lo obrado por quienes lo repusieron en el poder, ello debido a la "«peligrosidad potencial» de la nueva forma de organización del poder político que se anunciaba en el horizonte y que

\footnotetext{
${ }^{5}$ FERNÁNDEZ SARASOLA, Ignacio. La constitución de Cádiz: Origen, contenido y proyección internacional. p. 146
} 
se pretendía que sustituyera a la forma normal y secular de la organización del poder político conocida en Europa: la Monarquía Absoluta." 6

\subsection{La soberanía nacional}

Inevitable resulta comenzar reproduciendo el Decreto I donde las Cortes Generales y Extraordinarias fijan el alcance que luego tendrá la propia Constitución de Cádiz, que como sostiene Fernández Sarasola, dicha Ley fundamental supuso una ruptura con el Antiguo Régimen que se sustentó en dos principios medulares: la soberanía nacional y la división de poderes. Ambos principios quedaron recogidos en el Decreto I de las Cortes de Cádiz.

DECRETO I de 24 de septiembre de 1810.

Los diputados que componen este Congreso, y que representan la Nación española, se declaran legítimos en Cortes generales y extraordinarias y que residen en ellas la soberanía nacional. Las Cortes generales y extraordinarias de la Nación española, congregadas en la Real Isla de León con la voluntad general, pronunciada del modo más enérgico y patente, reconocen, proclaman y juran fidelidad al legitimo Rey al Señor D. Fernando VII de Borbón; y declaran nula de ningún valor ni efecto la cesión hecha en favor de Napoleón, no sólo por la violencia que intervino en aquellos actos injustos e ilegales por faltarle el consentimiento de la Nación. No conviniendo queden unidos el Poder legislativo, el ejecutivo y el judiciario, declaran las Cortes soberanas, que se reserva el ejercicio del Poder legislativo en toda su extensión.

(...) El Consejo de Regencia (...) reconocerá la soberanía nacional de las Cortes y jurará obediencia que de ellas emanaren, a cuyo fin pasará, inmediatamente que se lo haga constar este decreto, a la Cortes que le esperan para este acto y se hallan en sesión permanente. Se declara que la fórmula del reconocimiento y juramento que ha de hacer el Consejo de Regencia ¿Reconocéis la soberanía de la Nación representada por los diputados de estas Cortes generales y obedecer sus decretos, leyes y constitución que se establezca según los santos fines para observarlos y hacerlos ejecutar? - ¿Conservar la independencia, libertad e integridad de la nación? defender la religión católica, apostólica, romana? - ¿El gobierno monárquico del reino? - ¿Restablecer en el trono a nuestro amado Fernando VII de Borbón? - ¿Y mirar por el bien del Estado? Si así lo hiciereis Dios os ayude, y si no seréis responsables con arreglo a las leyes.

${ }^{6}$ PÉREZ ROYO, Francisco J. Del derecho político al derecho constitucional: Las garantías constitucionales. p. 235 
La importancia, trascendencia y consecuencias de los primeros días de actividad de las Cortes de la Real Isla de León, entre el día 24 y el 27 de septiembre, es representada por A. Ramos ${ }^{7}$ cuando sostiene que "En ocasiones se ha planteado como fue posible que en la primera sesión de las Cortes, en una jornada que duró más de quince horas, se adoptarán, casi sin discusión, por aclamación, medidas tan revolucionarias; y que apenas veinte días después ya discutieran el borrador del decreto de la libertad de imprenta. Pero el asunto es más fácil de entender si recordamos que durante algo más de dos años muchos españoles asumieron que la soberanía había vuelto a sus manos, puesto que el proceso que conduce a la recuperación de la soberanía por las Cortes, ratificado en la Constitución de 1812, comenzó, prácticamente, con la revuelta de Aranjuez iniciada la noche del 17 de marzo de 1808, la disputa dinástica por el trono entre Carlos IV y Fernando VII, las renuncias de Bayona, que propiciaron que la corona española pasara a José Bonaparte y la sublevación generalizada contra el ejército francés en los últimos días del mes de mayo."

Por su parte, como primer acto, los diputados de las Cortes de Cádiz se declararon a si mismos como titulares de la representación de la nación, de España, de modo que asumían sobre sí el ejercicio de la soberanía. Como sostiene Jaime Rodríguez "fue el principio de una gran revolución política"

Se establece, entonces, el principio de representación de los Diputados como articulación política y jurídica de la soberanía nacional. De este modo, la Soberanía Nacional queda establecida cuando se declara nula la cesión de la Corona por faltar el consentimiento de la Nación. La inviolabilidad de los diputados no se establece artificiosamente, sino que como manifestación de la soberanía nacional al ser aquellos representantes de la Nación toda, esto en el ejercicio de sus funciones, que como más tarde será explicitado (Decreto $N^{\circ} 13$ ) si son responsables por los delitos civiles y criminales que cometieses.

Referente al concepto de Nación se insiste que es la reunión de los españoles de ambos hemisferios, o bien el conjunto de los ciudadanos, ya que la gran revolución y quiebre con el antiguo régimen de los procesos norteamericano, francés y español es el establecimiento de la ciudadanía como base del principio de igualdad que otorga derechos, es decir todos los ciudadanos son iguales, y no se tienen derechos como privilegios por pertenecer a un determinado grupo social. Así lo asume la Constitución española en su título I, aún cuando existen diferencias entre los españoles, toda vez que no todos son ciudadanos, de modo que el goce de los derechos políticos solo corresponde a estos últimos. De igual modo las limitaciones para las mujeres eran claras, incluso se dictó la prohibición de que ellas ingresaran a las Cortes, incluso como público, prohibición que se dicta el 26 de septiembre de 1810. A pesar de que estas limitaciones a la luz de los parámetros actuales son inaceptables, hay que utilizar el prima histórico para

\footnotetext{
${ }_{8}^{7}$ RAMOS SANTANA, Alberto. 1810: Opinión pública y soberanía nacional.

8 "It was the beginning of a great political revolution". RODRíGUEZ O., Jaime E. "Equality! the sacred right of equality: Representation under constitution of 1812". p. 112
} 
darles unas correcta evaluación toda vez que el cambio en las instituciones en la época debe ser considerada como uno de los engranajes que han contribuido a lo largo de la historia al desarrollo, protección y promoción de los derechos y libertades públicas.

Como sostiene Clavero El término Nación es entonces indicativo de la propia concepción constitucional, de su principio de autodeterminación de una sociedad o de su no subordinación normativa a instituciones preconstituidas, incluida o ante todo la propia Monarquía. Es de este modo en que el nuevo orden se refleja en el orden de articulación de los poderes y funciones del Estado. Como sostenía Marx, el contenido propio del Estado absoluto se encontraba tan ligado e identificado al propio monarca que "El más importante acto constitucional del rey es, en consecuencia, su actividad sexual, pues mediante ella hace un rey, y perpetúa su cuerpo. El cuerpo de su hijo es la reproducción de su propio cuerpo, la creación de un cuerpo regio"', y que en virtud de la soberanía nacional retorna a su lugar, a la individualidad de un miembro más del cuerpo nacional.

\section{LA SEPARACIÓN DE PODERES}

Ya promulgada la Constitución en marzo de $1812^{10}$, se comenzó con un nuevo orden, un proceso que sólo podía alcanzarse por medio de la acción de un

${ }^{9}$ PÉREZ ROYO, Francisco J. Alcance y límites de la primera crítica de Marx a la teoría clásica del estado. p. 58

${ }^{10}$ Ya en su Discurso Preliminar: "Hecho cargo el Congreso de estas razones, pasa la Comision á exponer brevemente los fundamentos de su obra. Para darle toda la claridad y exâctitud que requiere la ley fundamental de un Estado, ha dividido la Constitucion en quatro partes, que comprehenden: Primera. Lo que corresponde á la Nacion como soberana é independiente, baxo cuyo principio se reserva la autoridad legislativa. Segunda. Lo que pertenece al Rey como participante de la misma autoridad y depositario de la potestad executiva en toda su extension. Tercera. La autoridad judicial delegada á los jueces y tribunales. Y quarta. El establecimiento, uso y conservacion de la fuerza armada y el orden económico y administrativo de las rentas y de las provincias. Esta sencilla clasificacion está señalada por la naturaleza misma de la sociedad, que es imposible desconocer, aunque sea en los gobiernos más despóticos, porque al cabo los hombres se han de dirigir por reglas fixas y sabidas de todos, y su formacion ha de ser un acto diferente de la execucion de lo que ellas disponen. Las diferencias ó altercados que puedan originarse entre los hombres se han de transigir por las mismas reglas ó por otras semejantes, y la aplicacion de éstas á aquéllos no puede estar comprendida en ninguno de los dos primeros actos. Del exâmen de estas tres distintas operaciones, y no de ninguna otra idea metafísica, ha nacido la distribucion que han hecho los políticos de la autoridad soberana de una Nacion, dividiendo su exercicio en potestad legislativa, executiva y judicial. La experiencia de todos los siglos ha demostrado hasta la evidencia que no puede haber libertad ni seguridad, y por lo mismo justicia ni prosperidad, en un Estado en donde el exercicio de toda la autoridad esté reunido en una sola mano. Su separacion es indispensable; mas los límites que se deben señalar particularmente entre la autoridad legislativa y executiva para que formen un justo y estable equilibrio son tan 
documento político, resultado imprescindible para poner control al poder del monarca. Como indica el Catedrático de Sevilla Pérez Royo "la Constitución es el presupuesto político para que exista un ordenamiento jurídico digno de tal nombre, esto es, el ordenamiento jurídico propio del Estado representativo, cuya manifestación más significativa es la codificación". ${ }^{11}$

Solo de este modo se pudo dar inicio a la articulación del poder, de modo de distribuirlo en distintos polos. Así, con relación a la situación gaditana y a la denominada separación de poderes (Artículos 15, 16 y 17 de la Constitución) se pueden dar diversas interpretaciones, en particular en el caso del poder judicial, ya que puede interpretarse por una parte que este no se constituye como un poder, sino que más que separación de poderes, en estos momentos, hubo una separación de funciones para efectos de la administración pública, debido a que todas las funciones se realizaban en nombre del Rey; o bien puede ser interpretado como una delegación de la Soberanía Nacional el que en virtud del delicado momento utilizaba la ficción del Rey como un elemento más bien simbólico.

Son las propias Cortes en su acto constituyentes quienes acuerdan un principio de separación de poderes o funciones de modo declarativo. Bartolomé Clavero

inciertos, que su establecimiento ha sido en todos tiempos la manzana de la discordia entre los autores más graves de la ciencia del gobierno, y sobre cuyo importante punto se han multiplicado al infinito los tratados y los sistemas. La Comision, sin anticipar el lugar oportuno de esta qüestion, no duda decir que absteniéndose de resolver este problema por principios de teoria política, ha consultado en esta parte la índole de la Constitucion antigua de España, por la que es visto que el Rey participaba en algún modo de la autoridad legislativa. La primera parte comienza declarando á la Nacion española libre y soberana, no sólo para que en ningún tiempo y baxo de ningún pretexto puedan suscitarse dudas, alegarse pretensiones ni otros subterfugios que comprometan su seguridad é independencia, como ha sucedido en varias épocas de nuestra historia, sino tambien para que los españoles tengan constantemente á la vista el testimonio augusto de su grandeza y dignidad, en que poder leer á un mismo tiempo el solemne catálogo de sus fueros y de sus obligaciones sin necesidad de expositores ni intérpretes. La Nacion, Señor, víctima de un olvido tan funesto, y no menos desgraciada por haberse dexado despojar por los ministros y favoritos de los reyes de todos los derechos é instituciones que aseguraban la libertad de sus individuos, se ha visto obligada á levantarse toda ella para oponerse á la más inaudita agresion que han visto los siglos antiguos y modernos; la que se habia preparado y comenzado á favor de la ignorancia y obscuridad en que yacian tan santas y sencillas verdades. Napoleon, para usurpar el trono de España, intentó establecer, como principio incontrastable, que la Nacion era una propiedad de la familia real, y baxo tan absurda suposicion arrancó en Bayona las cesiones de los reyes padre é hijo. V.M. no tuvo otra razon para proclamar solemnemente en su augusto decreto de 24 de septiembre la soberania nacional y declarar nulas las renuncias hechas en aquella ciudad de la corona de España por falta del consentimiento libre y espontáneo de la Nacion, sino recordar á ésta que una de sus primeras obligaciones debe ser en todos tiempos la resistencia á la usurpacion de su libertad é independencia. La sublime y heróyca insurreccion á que ha recurrido la desventurada España para oponerse á la atroz opresion que se la preparaba es uno de aquellos dolorosos y arriesgados remedios á que no puede acudirse con freqüencia sin aventurar la misma exîstencia política que por su medio se intenta conservar. Por tanto, la experiencia acredita, y aconseja la prudencia, que no se pierda jamas de vista quanto conviene á la salud y bienestar de la Nacion, no dexarla caer en el fatal olvido de sus derechos, del qual han tomado orígen los males que la han conducido á las puertas de la muerte."

${ }_{11}$ PÉREZ ROYO. Del derecho político al derecho constitucional: Las garantías constitucionales, p. 233 
sostiene que en virtud de la Constitución de Cádiz No estamos ya ante una Monarquía que dispensa limitadamente un orden y que retiene expansivamente un poder. Estamos ante una norma que reparte juego.

Así al entrar al análisis de las disposiciones relativas a la separación de poderes, es el mismo B. Clavero quien ha destacado que la propia secuencia en el tratamiento y desarrollo de la Constitución manifiesta un orden de distribución y articulación del poder. Es en el Capítulo III del la Constitución de Cádiz donde lo podemos apreciar en su magnitud:

“Del Gobierno.

Art. 13. El objeto del Gobierno es la felicidad de la Nación, puesto que el fin de toda sociedad política no es otro que el bienestar de los individuos que la componen.

Art. 14. El Gobierno de la Nación española es una Monarquía moderada hereditaria.

Art. 15. La potestad de hacer las leyes reside en las Cortes con el Rey.

Art. 16. La potestad de hacer ejecutar las leyes reside en el Rey.

Art. 17. La potestad de aplicar las leyes en las causas civiles y criminales reside en los Tribunales establecidos por la ley."

Importante es destacar que desde la discusión de las facultades de las Cortes se hace considerado que en ellas residía la soberanía nacional lo que se manifestó con toda claridad en distintas instituciones, entre las que cabe destacar la facultad de proponer y decretar las leyes, e interpretarlas y derogarlas, la convocatoria de pleno derecho dentro del plazo de un año, aún cuando el Rey no las haya convocado, el derecho de veto del Rey sobre las leyes es más bien simbólico, muy similar al consagrado en la Constitución de 1978, toda vez que la sanción del Rey es meramente simbólica para estos efectos, volveremos sobre esto.

Respecto al ejecutivo se consagra la figura del Rey como sagrada, inviolable y no sujeta a responsabilidad. Respecto a este último punto quienes respondían políticamente antes las Cortes eran los Secretarios de Despacho, quienes siendo responsables políticos, asumen los costos por el Rey, aún cuando no en su nombre. Las facultades del Rey se encontraban limitadas en el marco de la primacía de las Cortes como soberanas, así la prohibición expresa de impedir la celebración de Cortes, la prohibición de abdicar al trono sin el permiso de las Cortes

Un importa aspecto donde se manifiesta la doctrina de la separación de poderes, y en particular la primacía de las Cortes por sobre el Rey, es en la dirección política del Estado, o en la función de conducción política, en la denominada indirizzo politico. Según sostiene Varela Suanzes ${ }^{12}$ la dirección política en el Estado

\footnotetext{
12 VARELA SUANZES CARPEGNA, Joaquín. Rey, corona y monarquía en los orígenes del constitucionalismo español: 1808-1814. p. 181
} 
constitucional recién diseñado, le correspondía a las Cortes y no a la Corona de manera primordial, pero no exclusiva. Ello lo argumenta con cinco razones:

1. Le correspondía en exclusiva a las Cortes la Reforma Constitucional, considerada como la decisión política más importante.

2. A través de decretos las Cortes podían regular aspectos del sistema político, que podían afectar a la Corona.

3. Por la automática sanción que recibían las leyes luego de transcurridos dos años desde su presentación al Rey, se transformaba en un mero trámite dicho procedimiento.

4. Las Cortes influían en la designación del Consejo de Estado, cual cumplía funciones ejecutivas.

5. El esquema judicialista fijado por las Cortes mermaba el papel que la Corona tenía sobre las decisiones judiciales.

Igualmente, se manifestaba la gran primacía de las Cortes sobre el Rey en la Reforma de la Constitución, la que según dispone la Constitución de Cádiz se encuentra íntegramente realizada por las Cortes con excepción de la participación real en el proceso de publicación de la ley, según disponía el Art. 384. Una diputación presentará el decreto de reforma al Rey para que la haga publicar y circular a todas las autoridades y pueblos de la Monarquía.

Por reforma de la Constitución debemos entender aquel mecanismo jurídicamente ordenado para dar una respuesta política por parte de la sociedad a las insuficiencias que puedan detectarse en el pacto constituyente. Tiene por objeto garantizar que en el procedimiento de reforma la voluntad del constituyente prevalezca y sea respetada, lo que se manifiesta por medio de las cláusulas que establecen un procedimiento agravado, de la modificación de una ley ordinaria. Por otra parte, obliga a la conformación de un consenso político que permite a las distintas fuerzas manifestarse como en el propio pacto constituyente, y por otra, el pronunciamiento del cuerpo electoral, de modo que se configura un procedimiento complejo para la reforma, a través del paralelismo de las formas. ${ }^{13}$

El Rey se encontraba excluido del proceso de elaboración de la Constitución, tanto por el principio de la soberanía nacional, como por la imposibilidad física de concurrir. En el caso de la Constitución de Cádiz, el Rey no tenía la facultad de iniciativa de reforma constitucional, por lo que tanto durante el proceso de las Cortes que proponían la reforma, como en aquellas que la promovían y resolvían, se encontraba al margen.

Por otra parte, otro de los elementos que manifiestan la firme primacía de las Cortes, y de la ley, era la limitación meramente formal a la que estaban sujetas aquellas para la reforma de la Constitución, ya que debían someterse

\footnotetext{
${ }^{13}$ Al respecto del principio del paralelismo de las formas el autor sostiene que: "Aunque tal principio es imposible alcanzar de manera absoluta, dada la irrepetibilidad del momento constituyente, las cláusulas de reforma tienden a aproximarse a él lo más posible, esto es, a aproximar el ejercicio de la función de reforma a la función constituyente". PÉREZ ROYO, Javier. Curso de derecho constitucional. p. 636
} 
exclusivamente al procedimiento allí señalado, pero sin consideración alguna a limites materiales, pudiendo mudarse todo aquello que se resolviese, incluso todo aquello relativo a la monarquía.

Tal como mencionáramos anteriormente uno de los fundamentos de varias de las reformas fue finalizar con los poderes intermedios de la sociedad que contribuían al Antiguo Régimen de abusos y concentración del poder político, no sólo en el Rey, sino que en los denominados señoríos. Una de las reformas utilizadas para estos efectos, socavar el orden de los poderes intermedios, fue la reforma territorial, la que consistía en divisiones territoriales más pequeñas para descentralizar y romper con los antiguos reinos, de modo que el municipio se transforma en protagonista de la administración de los territorios. Otra reforma que contribuye a lo anterior es la relativa a las contribuciones, se prohíben los impuestos interiores de modo de terminar con los privilegios impositivos, suprimiéndose los 101 impuestos del Antiguo régimen y consignándose un impuesto proporcional a la capacidad económica que tendría el carácter de único para todos los españoles.

De igual modo, se establece un servicio militar obligatorio para cumplir un doble objetivo, debilitar el poder de los ejércitos mercenarios de los señoríos, y por otro mantener una fuerza permanente y renovada frente a la débil situación institucional. Las reformas anotadas son a mi juicio de de profunda trascendencia revolucionaria, ya que el Constituyente de Cádiz no sólo buscaba el ordenamiento institucional del país mediante la dictación de la nueva Constitución, sino que denotan el trasfondo firmemente rupturista con el orden establecido que los sectores liberales logran llevar a cabo. Por ello, no resulta extraño ni antojadizo que al retorno del "deseado" este barriera con lo obrado por el Constituyente gaditano, como muestra el simbólico, pero no menor, trato que recibían las Cortes en ausencia del Rey, el de Su Majestad, cuestión que ya perturbaba a Fernando VII durante su "secuestro".

Otro de los temas que a mi juicio resulta trascendente, el es debate sobre la administración local sobre los territorios americanos, ya que desde fines de 1810 Méxia Lequerica propone el reconocimiento de las Juntas formadas en América, lo que como hemos mencionado forma parte de un conflicto mayor que desembocará en los procesos de independencia pos constitución de Juntas leales a Fernando VII, en la mayoría de los territorios americanos.

En concordancia con lo anterior es que para intentar aplacar las revueltas que se producían en América, se convocaron a elecciones para los representantes a Cortes, lo que sin embargo aplaco mínimamente los procesos ya iniciados de independencias ya que quienes participaban como representantes y sus respectivos sectores sociales y políticos, tenían en muchos casos controversias políticas internas y luchas de pode, las que colaboraron a los estallidos insurgentes o independentistas. A pesar de esto, la Constitución acatada en la mayoría de los sitios a partir de septiembre de 1812, con ciertas excepciones como el caso de Chile. 
Irene Castells hace una conceptualización política e histórica de la Constitución de 1812 sosteniendo que era una constitución autóctona, no importada, como lo fue en otras partes, por los ejércitos franceses, elaborada para instaurar un orden nuevo y consolidar la revolución liberal, e impuesta al Rey.

De modo tal que debido a las condiciones que se vivían en particular en el sur de Europa, donde los modelos de dominación feudales, se encontraban fuertemente amenazados por estos movimientos, es que el surgimiento de la nueva clase burguesa, que tenía aspiraciones de copar el aparato estatal, y una nueva capa de terratenientes que pretendían hacer producir la tierra en provecho personal donde la idea de la propiedad privada y la libertad dominaban, es que permitió la incubación y fuerte desarrollo del modelo capitalista, el que como ha demostrado en la historia, no sucumbe ante nada. Así es que la autora sostiene que en virtud del nuevo modelo económico y la gran resistencia de las potencias de la Santa Alianza el propio proceso de cambio se aceleró. De este modo la necesaria limitación de los poderes del monarca, tenían un trasfondo no sólo filosófico, sino que también económico. Respecto a la organización de la resistencia, hace presente la reorganización de las élites, las que mediante sociedades secretas propugnaban el cambio. Existió una férrea persecución a ellas por parte de las Monarquías y de la Iglesia, toda vez que, como hemos dicho, estas se veían perjudicadas por las trasferencias de las tierras, y la desconcentración del poder político.

\section{CONCLUSIONES}

El concepto de la separación de poderes, con sus distintas significancias, evolución y consecuencias, no permite duda alguna que desde sus inicios ha tenido como objeto la libertad de los individuos mediante el control del poder político.

Ahondando en la Constitución de Cádiz, el concepto de la tecnificación de la separación de poderes, es producto del reconocimiento de la soberanía nacional.

Respecto a la soberanía, sobre el concepto de Bodín, lo que la caracteriza es la perpetuidad y carácter absoluto del poder de modo de provocar una única administración. En un primer momento histórico, con motivo de la concentración del poder en manos del Monarca Absoluto es que se comienzan a desarrollar aquellas teorías relativas al control del poder político producto de, por una parte de la imposibilidad de controlarlo y poner coto a los excesos y abusos; y por otra parte de la imposibilidad que tenían ciertos estamentos sociales de participar en el gobierno y ser parte del poder político de modo de atender mejor a sus intereses.

El desarrollo y convivencia de las sensibilidades adictas el régimen anterior y los reformistas, no fue fácil, tal como lo señalaba Francisco Tomás y Valiente, quien sostenía que en especial para los liberales españoles el dogma de la separación de poderes, en términos funcionales no era aceptado con simpleza, manifestado por ejemplo, en la enorme desconfianza hacia los jueces del Antiguo Régimen 
(cuestión coincidente con lo ocurrido en los Estados Unidos, que determina en gran medida su régimen de control de las leyes), así sostenía con claridad que "La contradicción entre cambio y estructuras jurídico-políticas y continuidad de las personas se planteó en Cádiz, no por la última, sino por primera vez en nuestra historia."

La nueva ordenación constitucional gaditana fue clara al establecer una relación de jerarquía entre los poderes, no siendo al azar la redacción, y el orden de cada uno de ellos en el texto constitucional. Esta prelación permite observar el entramado doctrinario en el que se construye el sistema, en base al principio de representación, es decir las Cortes como órgano delegado y permanente de la soberanía nacional. Es este último concepto el que provoca la separación de poderes. Así se declara el principio de la soberanía nacional, firme y claramente establecido en la Constitución de Cádiz, separando en primer lugar su dependencia a toda familia o persona, declarando que la Soberanía reside esencialmente en la Nación, y por lo mismo pertenece a ésta exclusivamente el derecho a establecer sus leyes fundamentales.

La prelación en la redacción del texto fundamental manifiesta la soberanía nacional y el principio de separación de poderes cual es el mecanismo donde aquella se articula orgánicamente. Es en los artículos 13 a 17 de la Constitución donde encontramos de la bóveda que guarda la clave del nuevo orden constitucional.

Como Castells sostiene con toda claridad que el fracaso de la estrategia constitucionalista de Cádiz se produjo porque ella se basaba en el intento de conciliar lealtad dinástica y revolución liberal, mediante algún tipo de monarquía constitucional. Intento inviable sin la colaboración del rey.

Sin embargo, nuevamente la historia demuestra que ciertos procesos son cíclicos, quien aprovecho en mayor medida los cambios de los procesos constitucionales liberales, fue la burguesía, al establecer las bases económicas del nuevo modelo, cuando logran, en muchos casos, pactar con los representantes del Antiguo régimen a fin de poner coto a los avances del progresismo liberal. Así el caso de los nuevos frentes que existieron en España en el Trienio Liberal, con los enfrentamientos entre doceañistas y veinteañistas.

A pesar de ello, las luces que aún siguen iluminando los más diversos rincones de la tierra, bajo los principios de libertad, igualdad y progreso provienen de una larga tradición de cambio que la Constitución gaditana supo recoger y transmitir jurídicamente, garantizando así su permanencia y trascendencia en el tiempo. 


\section{BIBLIOGRAFÍA}

(1987) ALONSO, Benjamín, "Del estado absoluto al estado constitucional", Manuscrits: Revista d'Història Moderna, no. 4, ISSN 0213-2397, pp. 81-90.

(1989) CASTELLS OLIVÁN, Irene, "La Constitución gaditana de 1812 y su proyección en los movimientos liberales europeos del primer tercio del siglo CIC", Trocadero: Revista de Historia Moderna y Contemporánea, no. 1, ISSN 02144212, Cádiz, pp. 117-132.

(2011) FERNÁNDEZ SARASOLA, Ignacio. La Constitución de Cádiz: Origen, contenido y proyección internacional, Centro de Estudios Políticos y Constitucionales, Madrid.

(1992) PÉREZ ROYO, Francisco Javier, "Del Derecho Político Al Derecho Constitucional: Las Garantías Constitucionales", Revista Del Centro De Estudios Constitucionales, no. 12, ISSN 0214-6185, pp. 233-249.

(1978) PÉREZ ROYO, Francisco Javier. "Alcance y límites de la primera crítica de Marx a la teoría clásica del estado". Revista De Estudios Políticos, no. 5, ISSN 0048-7694. pp. 51-76.

(2007) PÉREZ ROYO, Javier. Curso de derecho constitucional. $11^{\text {a }}$ ed., Ed. Marcial Pons, Madrid.

(2010) RAMOS SANTANA, Alberto, 1810: Opinión pública y soberanía nacional, Ed. Universidad de Cádiz.

(2008) RODRÍGUEZ O., Jaime E. "Equality! the Sacred Right of Equality: Representation Under Constitution of 1812". Revista De Indias, vol. 68, no. 242, ISSN 0034-8341, pp. 97-122.

(1995) VARELA SUANZES CARPEGNA, Joaquín, "Los modelos constitucionales en las Cortes de Cádiz", Revoluciones hispánicas: independencias americanas y liberalismo español, 1ra. ed. Universidad Complutense, Ed. Complutense, pp. 243268.

(1987) VARELA SUANZES CARPEGNA, Joaquín. "Rey, corona y monarquía en los orígenes del constitucionalismo español: 1808-1814", Revista de estudios políticos, no. 55, ISSN 0048-7694, pp. 123-196. 